\section{nephron \\ Clinical}

Practice
Nephron 2016;134:64-72

DOI: 10.1159/000447784
Received: February 24, 2016

Accepted after revision: June 21, 2016

Published online: July 16, 2016

\title{
Rate of Decline of Kidney Function, Modality Choice, and Survival in Elderly Patients with Advanced Kidney Disease
}

\author{
Shahid M. Chandna ${ }^{\mathrm{a}}$ Lewis Carpenter ${ }^{\mathrm{b}}$ Maria Da Silva-Gane ${ }^{\mathrm{a}} \quad$ Paul Warwicker $^{\mathrm{a}}$ \\ Roger N. Greenwood ${ }^{a}$ Ken Farrington ${ }^{a, b}$ \\ ${ }^{a}$ Renal Unit, Lister Hospital, Stevenage, and ${ }^{b}$ Centre for Health Services and Clinical Research, University of \\ Hertfordshire, Hatfield, UK
}

\section{Key Words}

Chronic kidney disease - Rate of decline of kidney

function - Conservative kidney management - Dialysis .

Modality choice $\cdot$ Survival

\begin{abstract}
Aim: In elderly, dependent patients with advanced chronic kidney disease, dialysis may confer only a small survival advantage over conservative kidney management (CKM). We investigated the role of rate of decline of kidney function on treatment choices and survival. Methods: We identified a retrospective (1995-2010) cohort of patients aged over 75 years, with progressive kidney impairment and an estimated glomerular filtration rate (eGFR) between 10 and $15 \mathrm{ml} /$ $\mathrm{min} / 1.73 \mathrm{~m}^{2}$. All subsequently chose to be treated by either dialysis or CKM. Patients were followed for a minimum of 3 years. Results: Of 250 patients identified, 92 (37\%) opted for dialysis and 158 (63\%) for CKM. Mean age was $80.9 \pm 4.0$ years. eGFR was $13.3 \pm 1.4$ initially and $8.7 \pm 3.0 \mathrm{ml} /$ $\mathrm{min} / 1.73 \mathrm{~m}^{2}$ at follow-up. Both were similar in those on dialysis and CKM pathways. Rate of decline of eGFR was more rapid in those choosing dialysis ( 0.45 (interquartile range, IQR 0.64) vs. 0.21 (IQR 0.28) $\mathrm{ml} / \mathrm{min} / 1.73 \mathrm{~m}^{2} /$ month, $\mathrm{p}<$ 0.001 ), and independently predicted choice of CKM. In pa-
\end{abstract}

\section{KARGER}

๑) 2016 S. Karger AG, Basel

E-Mail karger@karger.com

www.karger.com/nef tients with high comorbidity, choice of dialysis was associated with a non-significant adjusted survival advantage of 5 months. Inclusion in models of time dependent eGFR during follow-up (eGFR $\left.R_{t d}\right)$ - a reflection of the rate of decline of kidney function - showed it to be independently associated with mortality risk in those on the CKM $(p<0.001)$ but not on the dialysis pathway. CKM pathway patients at the 25 th centile of eGFR $\mathrm{td}_{\mathrm{td}}$ had an adjusted survival of 7 months compared to 63 months for those at the 75th centile. Conclusions: Rate of decline of kidney function is a determinant of CKM choice in elderly patients and is associated with mortality risk in patients of the CKM pathway. These findings should inform counselling.

(c) 2016 S. Karger AG, Basel

\section{Introduction}

Over the last 50 years, renal replacement therapy by dialysis has emerged as a life sustaining treatment for patients with advanced chronic kidney disease (CKD). In later years, in the developed world, the therapy has been widely available to all who may potentially benefit from it, and the numbers receiving these treatments have increased dramatically particularly in the elderly [1-3].
Dr. Ken Farrington

Renal Unit, Lister Hospital Coreys Mill Lane

Stevenage SG1 4AB (UK)

E-Mail ken.farrington@nhs.net 
However, there are problems. Dialysis imposes considerable burdens [4]. It is invasive, time consuming, both in terms of time spent attached to machines and time spent waiting and travelling, there is considerable morbidity associated with dialysis related symptoms, prolonged postdialysis recovery times and mortality remains high [5]. This is especially so among the elderly. Indeed for elderly, dependent patients, with substantial extra-renal comorbidity, the additional burdens imposed by dialysis can be overwhelming. For such patients, rehabilitation tends to be limited and prognosis can be poor $[4,6]$.

Some patients in these circumstances choose to forego dialysis and opt for conservative kidney management (CKM) [7-11]. The aim of CKM is to offer a comprehensive package of care focused not on life-extension but on supportive management, maintenance of quality of life and control of symptoms [12]. There are an increasing number of CKM programmes, throughout the UK [13] and beyond [14-16], which offer such provision. It is important here to rehearse the distinction between a rational/appropriate choice to forego a therapy in circumstances in which it is likely to be futile or in other ways detrimental to patient well-being, as opposed to rationing. Rationing imposes limits on the access to potentially useful interventions in order to save money [4]. This presents a stark contrast to an individual making an informed choice to forego an invasive treatment such as dialysis in favor of a more conservative option.

It has been shown that patients opting for CKM are in general much older, more dependent and, in many studies, tend to be more highly comorbid than those opting for dialysis [7]. In addition a number of studies, though limited, have suggested that in elderly dependent patients with high comorbidity, dialysis may confer only a small survival advantage overall [7,9-11] or in terms of hospital-free days $[8,17]$. Such findings can make an important contribution to shared decision making about choice of modality in this setting, but clearly much more information is required to truly inform this process.

It has been suggested that the rate of decline of kidney function tends to be less in older people with CKD than in their younger counterparts $[18,19]$. We undertook this retrospective study to examine the extent to which the rate of kidney functional decline influenced modality choice (dialysis or CKM) and how estimated glomerular filtration rate (eGFR) affects the survival of elderly patients over time with advanced CKD in both these treatment modalities.

Kidney Function and Survival in Elderly Patients with CKD

\section{Methods}

\section{Patients}

We reviewed the computerized records of all patients with progressive CKD who had attended our nephrology clinics between January 1, 1995, and January 1, 2010. We selected all the elderly patients who had progressed to stage $5 \mathrm{CKD}$, progression being defined as having at least one value of eGFR in the range $10-15 \mathrm{ml} /$ $\mathrm{min} / 1.73 \mathrm{~m}^{2}$ and subsequent values of eGFR consistently $<15 \mathrm{ml} /$ $\mathrm{min} / 1.73 \mathrm{~m}^{2}$. All were over the age of 75 years at the date of entry into stage 5. Patients were excluded if they had not been seen in our clinics prior to dialysis initiation or if they had presented with an eGFR $<10 \mathrm{ml} / \mathrm{min} / 1.73 \mathrm{~m}^{2}$. Patients with acute kidney injury were excluded. Patients were designated as being on dialysis or CKM pathways. Those on the dialysis pathway were those who had been subsequently commenced with hemodialysis (HD) or peritoneal dialysis (PD) or had made a decision to commence and had begun preparations but had died before initiation. Those on the CKM pathway were those who had subsequently made a decision to forego dialysis, should their CKD continue to progress. The project was carried out as an audit of clinical practice. Hence, ethical review was not sought (NHS Health Research Authority document 'Defining Research') [20].

\section{Modality Choice}

Patients were offered a free choice of modality constrained only by clinical and social imperatives. The process of modality choice involved referral of patients with progressive CKD (usually in late stage 4) to our multidisciplinary liaison team for assessment, education, counselling and support. This involved multiple interactions with individual patients and family members/carers and at least one visit to the patient's home. After subsequent discussions within the multidisciplinary team, treatment options were discussed with each patient and significant others and an individualized treatment plan agreed upon.

\section{Conservative Kidney Management}

Patients opting for CKM were offered ongoing support by the multidisciplinary team in liaison with community, primary care and hospice services as appropriate. Full medical treatment was continued.

\section{Dialysis Programme}

Patients opting for HD received thrice-weekly high-flux HD or online hemodiafiltration (40\%). The dialysis prescription for both $\mathrm{HD}$ and PD took into account the contribution of natural kidney function (urea clearance). Target total two-pool Kt/V urea (Kt/ $\left.\mathrm{V}_{\text {Total }}\right)$ was 1.2 per session. Those opting for PD were treated by continuous ambulatory PD or automated PD. Minimum weekly $\mathrm{Kt} / \mathrm{V}_{\text {Total }}$ target for both was 2.0.

\section{Data Collected}

The following information was obtained in a retrospective review of medical records on all patients:

(i) Date of entry into stage $5 \mathrm{CKD}$ - defined as the date of the first eGFR in the range $10-15 \mathrm{ml} / \mathrm{min} / 1.73 \mathrm{~m}^{2}$, provided the subsequent values were consistently $<15 \mathrm{ml} / \mathrm{min} / 1.73 \mathrm{~m}^{2}$. This was designated the 'index date';

(ii) Age - at entry into stage 5 CKD (see (i)). This was designated 'index age'; 
(iii) Gender;

(iv) Ethnicity - defined as white/non-white;

(v) Primary renal diagnosis;

(vi) Presence of diabetes mellitus;

(vii) The presence and severity of any extra-renal comorbidity at the index date. Subjects were attributed a score of $0-4$ in the following condition categories according to comorbidity severity: cardiac disease, peripheral vascular disease, cerebrovascular disease, respiratory disease and cancer. Cirrhosis was scored as a 4 . Scores were summed. Patients with scores of 4 in one condition category or with total scores $>4$ were designated as having high comorbidity. Those with lower scores were designated low comorbidity;

(viii) Serum creatinine level and eGFR (calculated by the MDRD-4 equation) at the index date (see (i)). These were designated 'index serum creatinine' and 'index eGFR', respectively;

(ix) Date of death between January 1, 1995, and January 1, 2013. Minimum follow was 3 years;

(x) Date of transfer to another center within in the same period;

(xi) Follow-up eGFR in dialyzed subjects was taken as the eGFR immediately prior to dialysis initiation, transfer to another center or immediately prior to death if this occurred before initiation. In CKM subjects, follow-up eGFR was taken as the eGFR immediately prior to death or transfer, or if still under follow-up, the eGFR immediately before January 1, 2013.

\section{Rate of Decline of Kidney Function}

Rate of decline of eGFR was calculated from the index eGFR and the follow-up eGFR. The difference in eGFR values was divided by the time difference (in months) between the estimates and expressed as $\mathrm{ml} / \mathrm{min} / 1.73 \mathrm{~m}^{2} / \mathrm{month}$ (henceforth abbreviated to $\mathrm{ml} / \mathrm{min} / \mathrm{month}$ ). In a small number of CKM patients, the kidney function did not fall from index up to the final eGFR. In these patients, the rate of fall of kidney function was taken as zero.

\section{Statistical Analysis}

Groups were compared using unpaired tests for normally distributed data and the Mann-Whitney U test for non-normally distributed data. For categorical data, Fisher's exact test was used to compare differences in proportions between groups. Predictors of the choice of modality (dialysis or CKM) were determined by logistic regression and the goodness of fit determined by use of the Nagelkerke R-squared. Rate of decline of kidney function was not normally distributed. Hence, the parameter was dichotomized around the median value for inclusion in the logistic regression analyses.

Survival was calculated from the index date - the date of the first recorded eGFR value in stage $5 \mathrm{CKD}$ - to death, transfer to another center or to the study end date of January 1, 2013. We estimated unadjusted survival in dialysis and CKM groups using Kaplan-Meier (K-M) models. Adjusted survival was estimated using Cox proportional hazards models. Model 1 included covariates that were chosen on a theory-based approach whereby known factors that have been shown to be important were included, as well as important covariates that were decided a priori. These were demographic (age, gender and ethnicity) and comorbid (high comorbidity and diabetes). Model 2 also included eGFR measured at 2 time points (study entry and follow-up) entered as a time varying covariate $\left(\mathrm{eGFR}_{\mathrm{td}}\right)$. To investigate the association between treatment choice (CKM or dialysis) and $\mathrm{eGFR}_{\mathrm{td}}$, both the main effects and an interaction term between the two were included in the model. With the exception of eGFR, which did vary over time, the proportional hazard assumption was checked between the 2 treatment groups using $\mathrm{K}-\mathrm{M}$ curves and an interaction term with time was entered into a model with all covariates included. The K-M plot found no overlap over time, and the lines ran parallel. No covariate had a significant interaction term with time. Schoenfeld residuals were also plotted against a zero slope and found to be non-significantly different. The proportional hazards assumption was therefore found to be appropriate. Data were analyzed using SPSS version 20 and Stata version 14 (StataCorp, USA).

\section{Results}

\section{Study Population}

Two hundred and fifty patients (table 1) met the eligibility criteria (67.2\% men and $93.2 \%$ white ethnicity). Mean age was $80.9 \pm 4.0$ years. Prevalence of diabetes was $27.2 \% ; 38 \%$ had high comorbidity. Mean index eGFR was $13.3 \pm 1.4 \mathrm{ml} / \mathrm{min} / 1.73 \mathrm{~m}^{2}$. Mean index serum creatinine was $374 \pm 55 \mu \mathrm{mol} / \mathrm{l}$. Primary renal disease was unknown in the majority (51\%) of cases. Renovascular disease (18\%), diabetic nephropathy (13\%), chronic obstructive uropathy (5\%) and others (including adult polycystic disease, 5\%) accounted for the remainder. Transfer to another center occurred in 4 cases.

\section{Modality Choice}

Ninety-two patients (37\%) opted for dialysis and 158 (63\%) for CKM (table 1). The relatively high proportion of CKM patients was contributed to by the exclusion of those presenting with advanced stage 5 CKD (late presenters including those presenting requiring urgent initiation of dialysis - 'crash-landers'). Those choosing dialysis included 8 patients who had opted for dialysis, started preparations, for example, by creation of an arteriovenous fistula, but had died before dialysis initiation. Patients who chose dialysis were significantly younger than those opting for CKM $(79.1 \pm 3.1$ vs. $82.0 \pm 4.1$ years, $\mathrm{p}<0.001$ ), a higher proportion were male (79vs. $60 \%, \mathrm{p}=$ 0.002 ) and fewer had high comorbidity ( 29 vs. $44 \%, \mathrm{p}=$ $0.025)$. There were no statistically reliable differences between modality groups with respect to ethnicity, the prevalence of diabetes or distribution of primary renal disease. Index eGFR did not differ between the groups though index serum creatinine was slightly higher in those choosing dialysis $(387 \pm 51$ vs. $366 \pm 56 \mu \mathrm{mol} / \mathrm{l}, \mathrm{p}=0.003)$. There was no difference between the groups with respect to the final follow-up eGFR. However, that distribution of follow-up GFR was different (table 2). More patients 
Table 1. Comparison of demographic and clinical factors between patients opting for dialysis and those opting for CKM

\begin{tabular}{|c|c|c|c|c|}
\hline & All & Dialysis & CKM & $\mathrm{p}$ value \\
\hline Number & 250 & $92(37 \%)$ & $158(63 \%)$ & \\
\hline Age, years & $80.9 \pm 4.0$ & $79.1 \pm 3.1$ & $82.0 \pm 4.1$ & $<0.001$ \\
\hline Male, \% & $168(67)$ & $73(79)$ & $95(60)$ & 0.002 \\
\hline White, \% & $232(93)$ & $87(95)$ & $145(92)$ & NS \\
\hline Diabetes, $\%$ & $68(27)$ & $21(23)$ & $47(30)$ & NS \\
\hline High comorbidity, \% & $96(38)$ & $27(29)$ & $69(44)$ & 0.025 \\
\hline Comorbidity score & $3(4)$ & $2(5)$ & $3(3)$ & 0.016 \\
\hline Index eGFR, $\mathrm{ml} / \mathrm{min} / 1.73 \mathrm{~m}^{2}$ & $13.3 \pm 1.4$ & $13.4 \pm 1.4$ & $13.3 \pm 1.4$ & NS \\
\hline Index serum creatinine, $\mu \mathrm{mol} / \mathrm{l}$ & $374 \pm 51$ & $387 \pm 51$ & $366 \pm 56$ & 0.003 \\
\hline Follow-up eGFR, $\mathrm{ml} / \mathrm{min} / 1.73 \mathrm{~m}^{2}$ & $8.7 \pm 3.0$ & $8.6 \pm 2.5$ & $8.8 \pm 3.2$ & NS \\
\hline Interval between eGFR estimates, months & $14.7(22.4)$ & $8.8(12.1)$ & $18.9(24.6)$ & $<0.001$ \\
\hline Rate of decline of eGFR, $\mathrm{ml} / \mathrm{min} / \mathrm{month}$ & $0.27(0.46)$ & $0.45(0.64)$ & $0.21(0.28)$ & $<0.001$ \\
\hline
\end{tabular}

Values presented as mean \pm SD for normally distributed continuous variables and as median (IQR) for nonnormally distributed variables. Values of categorical variables are presented as absolute values (percentages).

Table 2. Distribution of follow-up eGFR in groups opting for dialysis and those opting for CKD

\begin{tabular}{llll}
\hline $\begin{array}{l}\text { Quartiles of } \\
\text { final eGFR, } \\
\mathrm{ml} / \mathrm{min} / 1.73 \mathrm{~m}^{2}\end{array}$ & $\begin{array}{l}\text { Dialysis, } \\
\mathrm{n}(\%)\end{array}$ & $\begin{array}{l}\text { CKM, } \\
\mathrm{n}(\%)\end{array}$ & $\begin{array}{l}\text { Total, } \\
\mathrm{n}(\%)\end{array}$ \\
\hline$<6.45$ & $18(19.6)$ & $44(27.8)$ & $62(24.8)$ \\
$6.45-8.52$ & $35(38)$ & $28(17.7)$ & $63(25.2)$ \\
$8.52-10.85$ & $24(26.1)$ & $39(24.7)$ & $63(25.2)$ \\
$>10.85$ & $15(16.3)$ & $47(29.7)$ & $62(24.8)$ \\
Total & $92(100)$ & $158(100)$ & $250(100)$ \\
\hline
\end{tabular}

opting for CKM had a follow-up eGFR in the lowest quartile $\left(<6.45 \mathrm{ml} / \mathrm{min} / 1.73 \mathrm{~m}^{2}\right)$ than those of opting for dialysis (27.8 vs. $19.6 \%)$. Similarly, more of those choosing CKM had a follow-up eGFR in the highest quartile $(>10.85$ $\mathrm{ml} / \mathrm{min} / 1.73 \mathrm{~m}^{2}, 29.7$ vs. $\left.16.3 \%\right)$. Also, the median time interval between eGFR measurements was significantly greater in patients choosing CKM (with a much wider interquartile range, IQR) resulting in a significantly lower rate of decline of eGFR in patients opting for CKM (0.21 (IQR 0.28) vs. 0.45 (IQR 0.64) $\mathrm{ml} / \mathrm{min} / \mathrm{month}, \mathrm{p}<$ 0.001 ; table 1$)$.

\section{Predictors of Choice of CKM}

Age at index date, gender, comorbidity and rate of decline of eGFR were independent predictors of modality choice (table 3). A choice of CKM was 33\% more likely for every year above the age of 75 years. Women and those
Table 3. Logistic regression model of predictors of choice of CKM in patients over the age of 75 years on entry into stage $5 \mathrm{CKD}$

\begin{tabular}{lrrr}
\hline & OR & p value & $95 \%$ CI \\
\hline Age at index date, years & 1.325 & $<0.001$ & $1.203-1.459$ \\
$\begin{array}{l}\text { Gender, female vs. male } \\
\text { High comorbidity (vs. low) }\end{array}$ & 2.897 & 0.004 & $1.410-5.952$ \\
$\begin{array}{l}\text { Rate of decline eGFR } \\
\quad \text { (below median) }\end{array}$ & 60.001 & $1.805-6.995$ \\
Constant & 0.000 & $<0.001$ & $3.197-12.367$ \\
\hline
\end{tabular}

Ethnicity, primary renal disease and diabetes were not significant in this model. Nagelkerke R-squared $=0.402$.

with high comorbidity were around 3 times more likely to choose CKM. Subjects with a rate of decline of eGFR less than the median were around 6 times more likely to choose CKM. Ethnicity, primary renal disease and presence of diabetes did not influence modality choice. The model explained around $40 \%$ of the variation in choice of CKM (Nagelkerke R-squared = 0.402).

\section{Survival}

Of the 250 patients, 227 deaths were recorded during follow-up.

\section{Unadjusted Survival}

Median survival in those on the dialysis pathway was 38.2 months (95\% CI 27.7-46.4) compared with 23.1 months (95\% CI 19.8-26.6) for those choosing CKM ( $\mathrm{p}<$ 0.001 ). K-M plots are shown in figure 1. Unadjusted sur- 
Fig. 1. K-M plot of unadjusted survival in patients over the age of 75 years who opted for treatment by dialysis $(n=92)$ or CKM $(\mathrm{n}=158)$.

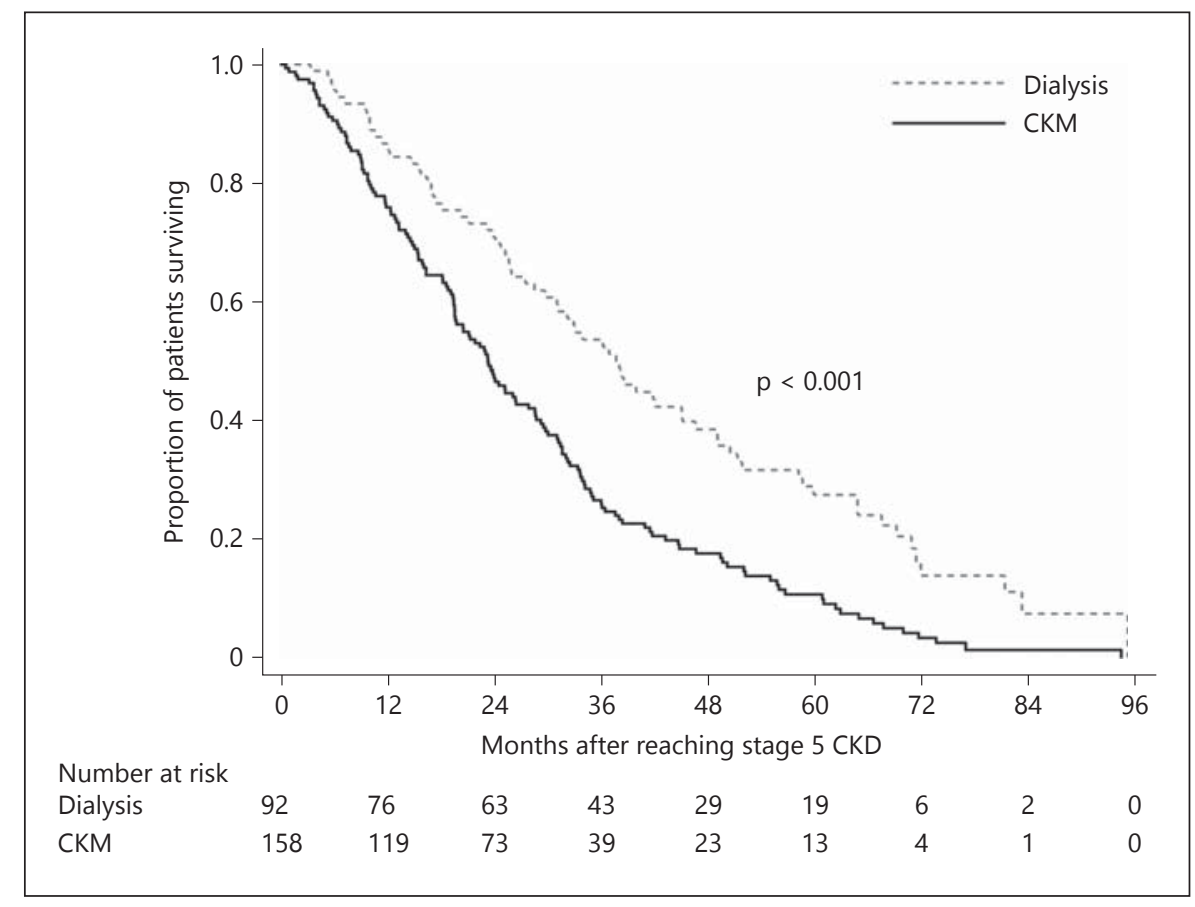

vival in patients with high comorbidity was also greater in those choosing dialysis (median survival 28.4, 95\% CI 19.6-37.2 vs. 20.3 months, $95 \%$ CI $17.5-23.2, p=0.049$ ), a survival benefit for dialysis of 8 months. Comparing survival of those on the dialysis pathway who had high comorbidity to that of all patients on the CKM pathway showed a non-significant $(\mathrm{p}=0.398)$ survival advantage for the dialysis group of 5 months $(28.4,95 \%$ CI 19.6-37.2 vs. 23.2 , 95\% CI 19.8-26.6).

\section{Adjusted Survival}

Model 1. Survival adjusted for age, gender, ethnicity, comorbidity and diabetes was also greater $(p<0.001)$ in those opting for dialysis (Model 1A - table 4; fig. 2a). The adjusted median survival advantage of the dialysis over the CKM pathway was 11 months (36 vs. 25 months). Confining the analysis to patients with high comorbidity (Model 1B - table 4; fig. 2b) showed a non-significant adjusted survival advantage for the dialysis over the CKM pathway of 5 months (26 vs. 21 months respectively, $\mathrm{p}=$ 0.093).

Model 2. We then explored the additional effect of kidney function on survival. Each of the 250 patients contributed 2 eGFR readings over the observation period, resulting in a total of 500 observations, which contributed a total of 8,383 months for use in the analysis. The model (table 5) contained terms for age, gender, ethnicity, co-
Table 4. Cox regression models of factors predicting survival time from entry into stage $5 \mathrm{CKD}$ in patients in patients over the age of 75 years

\section{HR p value $95 \% \mathrm{CI}$}

\section{Model $1 \mathrm{~A}$}

Age at index date, years $\quad 1.076 \quad<0.001 \quad 1.037-1.117$ $\begin{array}{llll}\text { Gender, female vs. male } & 0.697 & 0.017 & 0.519-0.936\end{array}$ Ethnicity (white vs. non-white) $0.766 \quad 0.367 \quad 0.429-1.366$ $\begin{array}{llll}\text { High comorbidity } \quad 1.844 & <0.001 & 1.392-2.444\end{array}$ $\begin{array}{llll}\text { Diabetes } & 1.353 & 0.045 & 1.006-1.818\end{array}$ Choice of CKM $\quad 1.877<0.001-2.586$

\section{Model $1 B$}

Age at index date, years $\quad 1.045 \quad 0.136 \quad 0.986-1.108$ $\begin{array}{llll}\text { Gender, female vs. male } & 0.771 & 0.284 & 0.479-1.241\end{array}$ Ethnicity (non-white vs. white) $0.826 \quad 0.752 \quad 0.252-2.704$ $\begin{array}{llll}\text { Diabetes } & 1.111 & 0.677 & 0.677-1.824\end{array}$ $\begin{array}{llll}\text { Choice of CKM } & 1.527 & 0.093 & 0.932-2.500\end{array}$

Model $1 \mathrm{~A}$ in whole group $(\mathrm{n}=250)-$ model significant $(\mathrm{p}<$ $0.001)$. Model $1 B$ in high comorbidity group $(n=96)-$ model non-significant $(\mathrm{p}=0.173)$.

morbidity, diabetes, choice of CKM and an interaction term between choice of modality and $\mathrm{eGFR}_{\mathrm{td}}$. In this model, those opting for CKM had greater than 2-fold increase in risk of death compared to those opting for dialysis (hazard ratio, HR 2.42, 95\% CI 1.65-3.53, p < 0.001). 


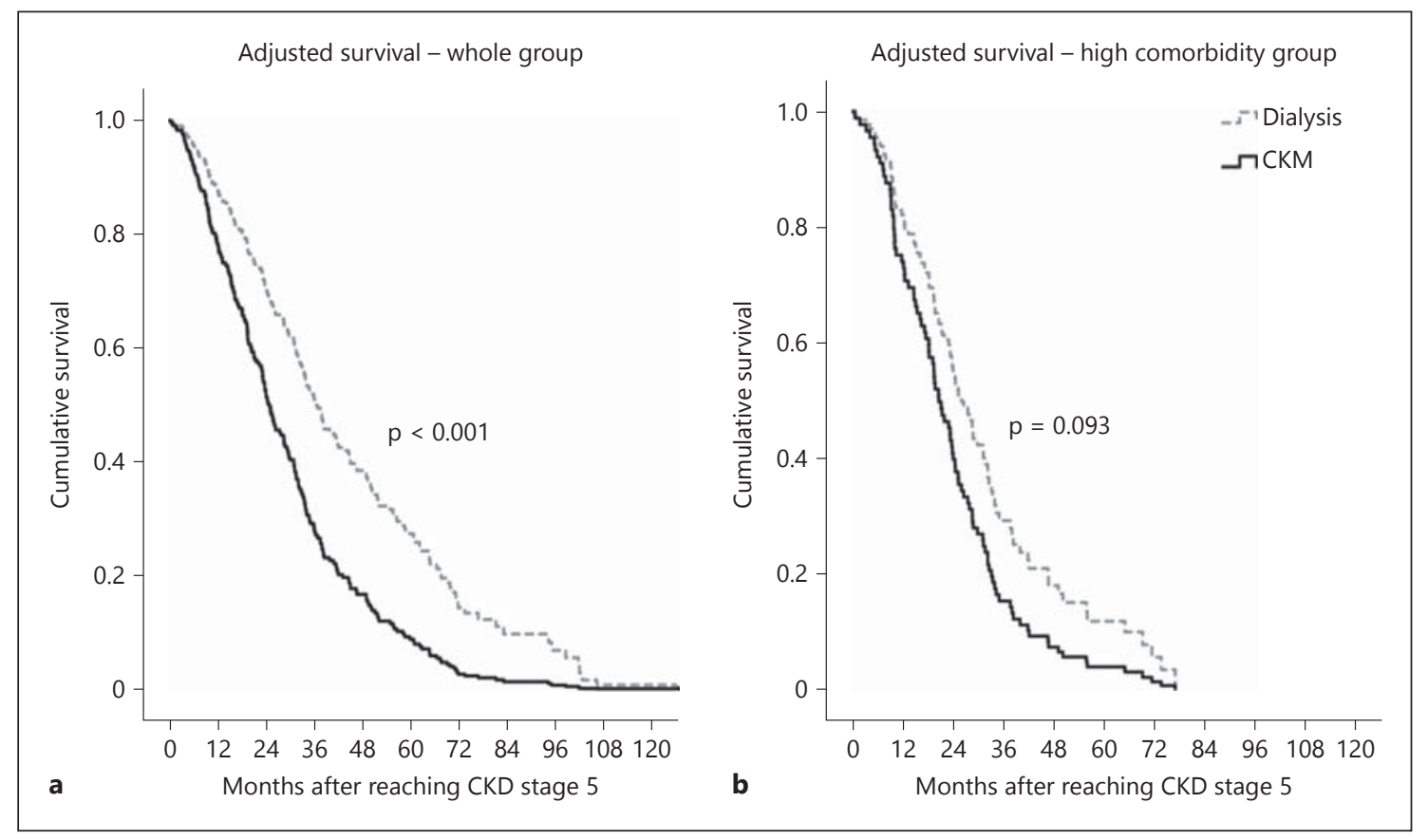

Fig. 2. Adjusted survival time in patients over the age of 75 years with stage 5 CKD. a Adjusted for age, gender, ethnicity, diabetes, high comorbidity and modality choice (dialysis or CKM). b Adjusted for age, gender, ethnicity, diabetes and modality choice (dialysis of CKM) in patients with high comorbidity.

Table 5. Cox regression models of factors predicting survival time from entry into stage 5 of 250 patients over the age of 75 years

\begin{tabular}{lrrr}
\hline Covariate & HR & p value & $95 \%$ CI \\
\hline CKM & 2.42 & $<0.001$ & $1.65-3.53$ \\
eGFR $_{\text {td }}{ }^{*}$ modality & & & \\
$\quad$ Dialysis & 0.95 & 0.282 & $0.88-1.04$ \\
$\quad$ CKM & 0.64 & $<0.001$ & $0.58-0.71$ \\
High comorbidity & 2.12 & $<0.001$ & $1.57-2.86$ \\
Age at index date, years & 1.04 & 0.039 & $1.00-1.08$ \\
Sex, male vs. female & 1.69 & 0.001 & $1.24-2.31$ \\
Ethnicity (non-white vs. white) & 0.92 & 0.776 & $0.50-1.68$ \\
Diabetes & 1.48 & 0.014 & $1.08-2.02$ \\
\hline
\end{tabular}

$\mathrm{eGFR}_{\mathrm{td}}{ }^{\#}$ modality is an interaction term to explore the separate effects of eGFR $\mathrm{td}_{\mathrm{td}}$ on adjusted mortality risk in patients who chose CKM and those who chose dialysis.

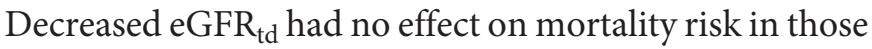
choosing dialysis (HR 0.95, 95\% CI 0.88-1.04, $\mathrm{p}=0.282$ ), but was associated with increased mortality risk in those on the CKM pathway (HR 0.64, 95\% CI 0.58-0.71, p < $0.001)$. Figure 3 illustrates the difference in mortality risk in these groups - in those with low (25th centile) and high (75th centile) levels of eGFR $\mathrm{td}_{\mathrm{td}}$. The median adjusted sur- vival of patients on the dialysis pathway who had low eGFR $_{\text {td }}$ was 38 months compared with 45 months for those with high eGFR $\mathrm{td}_{\mathrm{td}}$. For patients on the CKM pathway with low eGFR $\mathrm{td}_{\mathrm{td}}$, the median survival was just 7 months compared with 63 months for those with high eGFR $\mathrm{td}_{\mathrm{td}}$.

\section{Discussion}

It has been previously suggested that in older patients with advanced CKD and high extra-renal comorbidity, survival may not be significantly enhanced by the choice of dialysis rather than by CKM [7-11]. In keeping with this, in this study, we have confirmed that in patients with high comorbidity, overall survival adjusted for the baseline factors of age, gender, ethnicity and the presence of diabetes seems to be only marginally improved by choice of dialysis. We have also demonstrated that patients opting for CKM tend to have a much slower rate of decline of eGFR than those opting for dialysis.

Leading on from this, we have proceeded to show that $\mathrm{eGFR}_{\mathrm{td}}$ in the model, in addition to these baseline factors, reveals major differences in adjusted survival between those opting for CKM and those opting for dialysis. Since mean index eGFR and mean follow-up eGFR were similar 
Fig. 3. Illustration of adjusted survival in elderly patients over the age of 75 years opting for dialysis or CKM stratified by $\mathrm{eGFR}_{\mathrm{td}}$. The 4 groups are those opting for CKM with low eGFR td $_{\text {(orange line), those }}$ opting for CKM with high $\mathrm{eGFR}_{\mathrm{td}}$ (green line), those opting for dialysis with low $\mathrm{eGFR}_{\mathrm{td}}$ (red line) and those opting for dialysis with high eGFR td $_{\text {(blue line). Low }}$ $\mathrm{eGFR}_{\mathrm{td}}$ represents patients with eGFR $\mathrm{td}_{\mathrm{td}}$ at 25 th centile. High eGFR td $_{\text {represents }}$ ratients with $\mathrm{eGFR}_{\mathrm{td}}$ at 75 th centile.

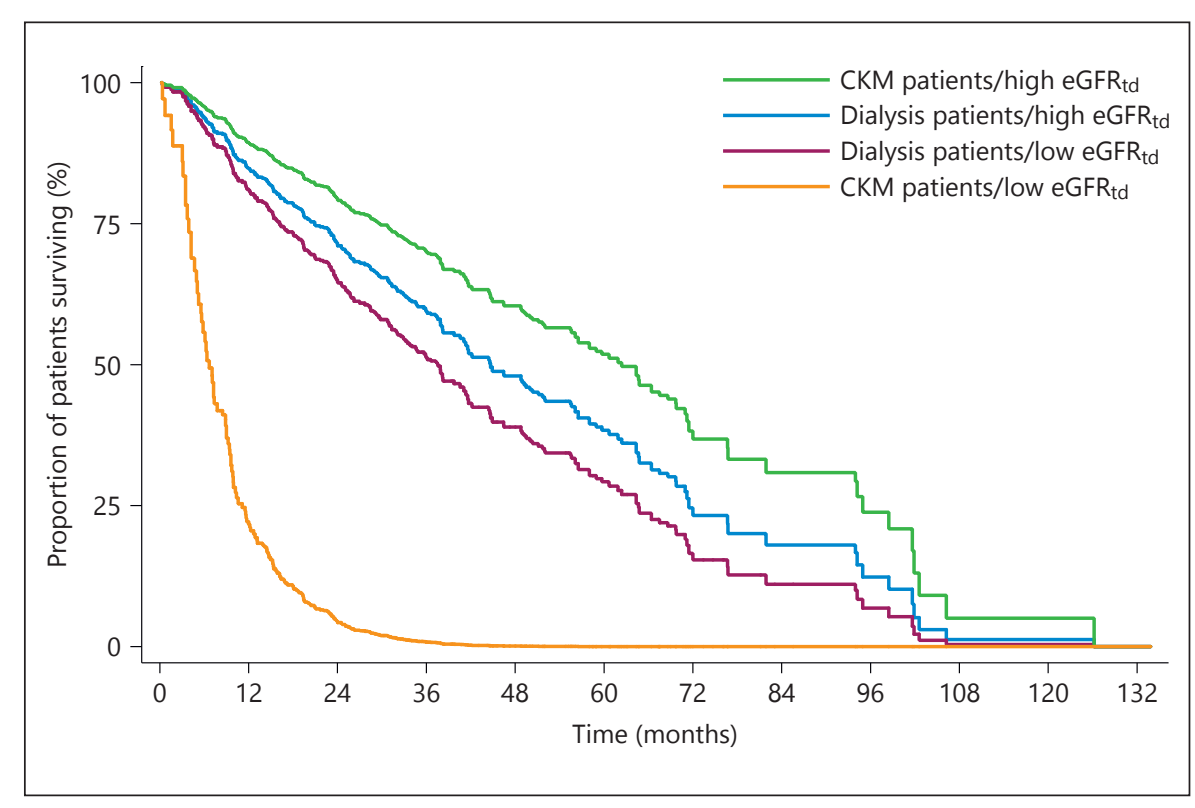

in those on dialysis and CKM pathways, differences in eGFR $_{t d}$ imply differences in the rate of decline of kidney function over follow-up, high $\mathrm{eGFR}_{\mathrm{td}}$, suggesting a slower rate of decline and low eGFR $\mathrm{td}_{\mathrm{td}}$ a more rapid rate. $\mathrm{eGFR}_{\mathrm{td}}$ has a small and non-significant survival effect in patients opting for dialysis. For instance, in patients with levels of eGFR $\mathrm{td}_{\mathrm{td}}$ at 25 th and 75 th centiles, adjusted survival was 38 and 45 months, respectively, for those on the dialysis pathway. The effect was much greater in those opting for CKM in whom the corresponding adjusted survival times were 7 and 63 months, respectively. The model thus suggests that, in contrast to patients with rapidly declining kidney function, those with slower rates of decline may fare better on the CKM rather than those on the dialysis pathway.

A proportion of patients opting for CKM may well have died before reaching a point at which dialysis would otherwise have been considered. Table 2 suggests that this proportion may be greater than the 8 of $92(8.7 \%)$ patients who opted for dialysis who died before initiation This emphasizes that the survival comparisons being made are between dialysis and CKM pathways rather than those which contrast CKM as an alternative to dialysis beyond the point at which dialysis would otherwise have been considered. These factors also highlight the heterogeneity of those choosing CKM and the problems of interpreting survival data in patients on this management pathway.

There are other ramifications for clinical practice. There is a need to emphasize the potential impact of the trajectory of kidney function on survival when counsel- ling elderly patients about modality choices. Decisions about whether to choose or CKM in this setting are highly complex and highly individual. As one of many factors that may need to be considered, information about rate of decline of kidney function and its potential influence on prognosis may contribute to shared decision making. Our findings also imply that comparisons of survival between cohorts of patients on CKM and dialysis should be adjusted for rate of decline of kidney function to allow adequate interpretation.

Our findings may also influence a number of other issues. For instance, interventions that may entail use of radiographic contrast materials, nephrotoxic antibiotics and surgical procedures, by compromising kidney function, may significantly increase mortality risk in these settings. Similarly, since dialysis initiation may compromise residual kidney function, unsuccessful trials of dialysis with subsequent dialysis withdrawal may contribute to a worse prognosis than would have pertained if a conservative approach had been pursued throughout. Mortality is particularly high in the early weeks of dialysis [6, 21-23]. These observations caution against the use of trials of dialysis in situations in which the potential benefits are unclear.

Most published studies comparing CKM and dialysis cohorts do not address the issue of trajectory of kidney functional decline. The notable exception is the study of Seow et al. [24], in which trajectory was higher at baseline in the dialysis cohort, though the focus was on comparative quality of life in CKM and dialysis patients rather than on survival. In another study, patients who had rap- 
id kidney functional decline were excluded [11]. There is evidence to suggest that the mean rate of decline of kidney function is slower in elderly patients whatever the level of kidney function $[18,19]$ and that in patients over the age of 84 years with an eGFR $<15 \mathrm{ml} / \mathrm{min} / 1.73 \mathrm{~m}^{2}$, the risk of death exceeds that of end-stage kidney disease [18]. These factors may have an important bearing on planning management for this group of patients.

There are a number of issues that need to be taken into account in the interpretation of our findings. The study was small and retrospective and thus subject to all the potential pitfalls associated with studies of this nature. Other issues include the limited assessment of comorbidities and the failure to control for frailty, performance status, nutritional status and cognitive impairment. The method of inferring rate of decline of kidney function relied on just 2 eGFR measurements. We recognize the limitations of this methodology, which was dictated by the limited follow-up data for a small proportion of these patients. The premise underlying the use of eGFR as an indicator of kidney function in this setting can also be questioned. The method is based on measurements of serum creatinine, which in this setting may be as reflective of muscle mass as of kidney function $[25,26]$, though this issue would relate similarly to those on the dialysis and CKM pathways. The difference in timing of the follow-up eGFR measurement may also be important, since the measurement in those on the CKM pathway was tak- en nearer to death. If, as a result, these patients had less muscle mass, this might result in falsely high final eGFR levels in these patients. This though might be expected to amplify the differences between the rates of renal functional decline in patients on these pathways. We also recognize that a rapidly falling GFR could constrain decision making and thus constitute another bias between groups.

In conclusion, we have found that the rate of decline of kidney function is a determinant of modality choice in elderly patients with advanced CKD. The trajectory of kidney function also seems to be a predictor of mortality in those opting for CKM. These factors may be helpful in counselling such patients about modality choice. Adjustment of outcome data for rate of decline of kidney function is also recommended.

\section{Disclosure Statement}

The authors declare that they have no competing interests. The results presented in this paper have not been published previously in whole or part, except in abstract format.

\section{Statement of Ethics}

This study did not require informed consent nor review/approval by appropriate Ethics Committee.

\section{References}

1 Rao A, Casula A, Castledine C: UK renal registry 17 th annual report: chapter 2 UK renal replacement therapy prevalence in 2013: national and centre-specific analyses. Nephron 2015;129(suppl 1):31-56.

-2 Pippias M, Stel VS, Abad Diez JM, Afentakis N, Herrero-Calvo JA, Arias M, Tomilina N, Bouzas Caamaño E, Buturovic-Ponikvar J, Cala S, Caskey FJ, Castro de la Nuez P, Cernevskis H, Collart F, Alonso de la Torre R, Garcia Bazaga Mde L, De Meester J, Diaz JM, Djukanovic L, Ferrer Alamar M, Finne P, Garneata L, Golan E, Gonzalez Fernández R, Gutierrez Avila G, Heaf J, Hoitsma A, Kantaria N, Kolesnyk M, Kramar R, Kramer A, Lassalle M, Leivestad T, Lopot F, Macario F, Magaz A, Martin-Escobar E, Metcalfe W, Noordzij M, Palsson R, Pechter U, Prutz KG, Ratkovic M, Resic H, Rutkowski B, Santiuste de Pablos C, Spustova V, Suleymanlar G, Van Stralen K, Thereska N, Wanner C, Jager KJ: Renal replacement therapy in Europe: a summary of the 2012 ERA-EDTA registry annual report. Clin Kidney J 2015;8:248-261.
3 USRDS: Chapter 10: United States Renal Data System: 2012 Annual Data Report: International Comparisons. Bethesda, United States Renal Data System, 2012.

-4 Chandna SM, Schulz J, Lawrence C, Greenwood RN, Farrington K: Is there a rationale for rationing chronic dialysis? A hospital based cohort study of factors affecting survival and morbidity. BMJ 1999;318:217-223.

5 Steenkamp R, Rao A, Roderick P: UK renal registry 17 th annual report: chapter 5 survival and cause of death in UK adult patients on renal replacement therapy in 2013: national and centre-specific analyses. Nephron 2015; 129(suppl 1):99-129.

6 Kurella Tamura M, Covinsky KE, Chertow GM, Yaffe K, Landefeld CS, McCulloch CE: Functional status of elderly adults before and after initiation of dialysis. N Engl J Med 2009; 361:1539-1547.

7 Smith C, Da Silva-Gane M, Chandna S, Warwicker P, Greenwood R, Farrington K: Choosing not to dialyse: evaluation of planned nondialytic management in a cohort of patients with end-stage renal failure. Nephron Clin Pract 2003;95:c40-c46.

-8 Carson RC, Juszczak M, Davenport A, Burns A: Is maximum conservative management an equivalent treatment option to dialysis for elderly patients with significant comorbid disease? Clin J Am Soc Nephrol 2009;4:1611-1619.

-9 Murtagh FE, Marsh JE, Donohoe P, Ekbal NJ, Sheerin NS, Harris FE: Dialysis or not? A comparative survival study of patients over 75 years with chronic kidney disease stage 5 . Nephrol Dial Transplant 2007;22:1955-1962.

10 Chandna SM, Da Silva-Gane M, Marshall C, Warwicker P, Greenwood RN, Farrington K: Survival of elderly patients with stage $5 \mathrm{CKD}$ : comparison of conservative management and renal replacement therapy. Nephrol Dial Transplant 2011;26:1608-1614.

11 Hussain JA, Mooney A, Russon L: Comparison of survival analysis and palliative care involvement in patients aged over 70 years choosing conservative management or renal replacement therapy in advanced chronic kidney disease. Palliat Med 2013;27:829-839.
Kidney Function and Survival in Elderly Patients with CKD 
12 Davison SN, Levin A, Moss AH, Jha V, Brown EA, Brennan F, Murtagh FE, Naicker S, Germain MJ, O'Donoghue DJ, Morton RL, Obrador GT: Executive summary of the KDIGO controversies conference on supportive care in chronic kidney disease: developing a roadmap to improving quality care. Kidney Int 2015;88:447-459.

13 Okamoto I, Tonkin-Crine S, Rayner H, Murtagh FE, Farrington K, Caskey F, Tomson C, Loud F, Greenwood R, O'Donoghue DJ, Roderick P: Conservative care for ESRD in the United Kingdom: a national survey. Clin J Am Soc Nephrol 2015;10:120-126.

14 Brown MA, Collett GK, Josland EA, Foote C, Li Q, Brennan FP: CKD in elderly patients managed without dialysis: survival, symptoms, and quality of life. Clin J Am Soc Nephrol 2015;10:260-268.

-15 O'Connor NR, Kumar P: Conservative management of end-stage renal disease without dialysis: a systematic review. J Palliat Med 2012;15:228-235.

16 Foote C, Kotwal S, Gallagher M, Cass A, Brown M, Jardine M: Survival outcomes of supportive care versus dialysis therapies for elderly patients with end-stage kidney disease: a systematic review and meta- analysis. Nephrology (Carlton) 2016;21: 241-253.

17 Da Silva-Gane M, Wellsted D, Greenshields $\mathrm{H}$, Norton S, Chandna SM, Farrington K: Quality of life and survival in patients with advanced kidney failure managed conservatively or by dialysis. Clin J Am Soc Nephrol 2012;7:2002-2009.

18 O'Hare AM, Choi AI, Bertenthal D, Bacchetti P, Garg AX, Kaufman JS, Walter LC, Mehta KM, Steinman MA, Allon M, McClellan WM, Landefeld CS: Age affects outcomes in chronic kidney disease. J Am Soc Nephrol 2007;18: 2758-2765.

19 Conway B, Webster A, Ramsay G, Morgan N, Neary J, Whitworth C, Harty J: Predicting mortality and uptake of renal replacement therapy in patients with stage 4 chronic kidney disease. Nephrol Dial Transplant 2009;24: 1930-1937.

20 Health Research Authority: Defining Research. 2013. http://www.hra.nhs.uk/documents/2013/ 09/defining-research.pdf.

21 Bradbury BD, Fissell RB, Albert JM, Anthony MS, Critchlow CW, Pisoni RL, Port FK, Gillespie BW: Predictors of early mortality among incident US hemodialysis patients in the dialysis outcomes and practice patterns study (DOPPS). Clin J Am Soc Nephrol 2007; 2:89-99.

22 Eckardt KU, Gillespie IA, Kronenberg F, Richards S, Stenvinkel P, Anker SD, Wheeler DC, de Francisco AL, Marcelli D, Froissart M, Floege J: High cardiovascular event rates occur within the first weeks of starting hemodialysis. Kidney Int 2015;88:1117-1125.

23 Foley RN, Chen SC, Solid CA, Gilbertson DT, Collins AJ: Early mortality in patients starting dialysis appears to go unregistered. Kidney Int 2014;86:392-398.

24 Seow YY, Cheung YB, Qu LM, Yee AC: Trajectory of quality of life for poor prognosis stage 5D chronic kidney disease with and without dialysis. Am J Nephrol 2013;37:231-238.

25 Beddhu S, Samore MH, Roberts MS, Stoddard GJ, Pappas LM, Cheung AK: Creatinine production, nutrition, and glomerular filtration rate estimation. J Am Soc Nephrol 2003;14: 1000-1005.

26 Wong MG, Pollock CA, Cooper BA, Branley P, Collins JF, Craig JC, Kesselhut J, Luxton G, Pilmore A, Harris DC, Johnson DW: Association between GFR estimated by multiple methods at dialysis commencement and patient survival. Clin J Am Soc Nephrol 2014;9: 135-142. 